\title{
Compact Dual Band Antenna Design for Ku / Ka Band Applications
}

\author{
Abhishek Kandwal ${ }^{1}$ \\ ${ }^{1}$ RF Electronics Laboratory, Wireless Information Security and Eco-Electronics Research Unit, \\ National Electronics and Computer Technology Center, NSTDA, Thailand \\ *corresponding author, E-mail: kandwal_abhishekerediffmail.com
}

\begin{abstract}
This communication proposes a compact $16 \mathrm{GHz} / 30 \mathrm{GHz}$ dual band antenna design for $\mathrm{Ku} / \mathrm{Ka}$ band applications. The antenna consists of two layers with lower layer having the fed patch and the upper layer having non-periodic element array. The antenna has been designed to operate at two different frequencies with compact dimensions of (8mm x 8mm) using Rogers RT 5880. The compact size of this proposed antenna also makes it suitable for integration with the microwave and millimeter wave circuits. The proposed antenna provides high radiation efficiency and a peak gain of about $8 \mathrm{~dB}$ at the resonant frequencies with reduced side lobe levels.
\end{abstract}

\section{Introduction}

Microstrip antennas have been widely used in wireless communication systems because they are low profile, light weight, low cost, conformal design, and easy to fabricate and integrate. Nowadays many researchers have found great interest in designing $\mathrm{Ku}-$ and Ka-band antennas and still face a major challenge to implement these applications [12]. Due to greater congestion in the lower frequency bands, it has become a necessity of the antenna development sector to move to higher frequencies so that the researchers can get a wider spectrum and more area. But as we move to higher frequency regions, other problems arise, like increased losses, atmospheric attenuation, size reduction, and many more. Due to all these, the antenna characteristics tend to degrade and hence it becomes very difficult to obtain better properties for antenna radiation. Size reduction is another issue due to which researchers find it very difficult to fabricate the prototypes [3-9]. Now days there are many techniques and instruments with which researchers can cop up with these types of issues, but still these are big challenges. Obtaining dual band or multiband characteristics is very useful for many antenna applications especially at higher frequencies. With the time these dualband antennas have been improved to face more challenging demands of the modern wireless communication systems that are capable of integrating more than one communication standard into a single system. These antennas are designed to be integrated in different array systems in which they can be operated at a single or multi frequency bands simultaneously [10-16].

In this communication, we have proposed a novel dual band two-layer antenna design especially designed for $\mathrm{Ku}$ and Ka-band applications and for integration with microwave and millimeter wave circuits. The antenna is very compact due to its small dimensions and consists of different sized array elements at the top layer of the structure. The antenna operating at two frequencies uses a non-periodic element array for achieving better characteristics. The radiation pattern of the antenna provides a maximum directivity of about $7.8 \mathrm{~dB}$ with a very good return loss. The antenna as a whole provides a good solution for high frequency applications with its dual band and good radiation characteristics.

\section{Antenna Design and Parameters}

2.1. The antenna geometry is shown in fig. 1. Antenna consists of two layers with first lower layer having the fed patch and the upper layer having an array of different sized elements. The antenna is fabricated over Rogers Duroid RT 5880 substrates with dielectric constant of 2.2 and thermal conductivity of $0.2 \mathrm{~W} / \mathrm{K} / \mathrm{m}$. The thickness of the dielectric layers is $0.8 \mathrm{~mm}$ each.

2.2. The first bottom layer consists of a slotted rectangular patch with conductive strip lines. The upper layer has been stacked to the lower layer at a gap of $1 \mathrm{~mm}$. Dimensions of the whole structure is $(8 \mathrm{~mm} \times 8 \mathrm{~mm})$ and the combined thickness of the two layers is $2.702 \mathrm{~mm}$ from the ground plane of the structure. The rectangular patch having dimensions of $(2 \mathrm{~mm} \times 5 \mathrm{~mm})$ and with a slot of $(1 \mathrm{~mm} \times$ $1 \mathrm{~mm}$ ), fed coaxially at a distance of $0.3 \mathrm{~mm}$ from center of the patch along Y-axis.

2.3. The antenna parameters have been optimized using 3D EM simulation software CST Studio Suite and experimentally tested using vector network analyzer.

2.4. Fig. 1(a) here shows the top view of the lower layer of proposed antenna. All the dimensions are clearly marked in the geometry including the feeding point i.e. $(0,0.3)$ along Y-axis. All the parameters have been obtained using standard numerical equations, mathematical models and extensive optimizations using 3D solver [7].

2.5. Fig. 1(b) here shows the top view of the upper layer of the proposed antenna. All the patches form an array of different sized elements. Fig. 2 shows the prototype of the antenna design with a two-layer structure and port extension. 


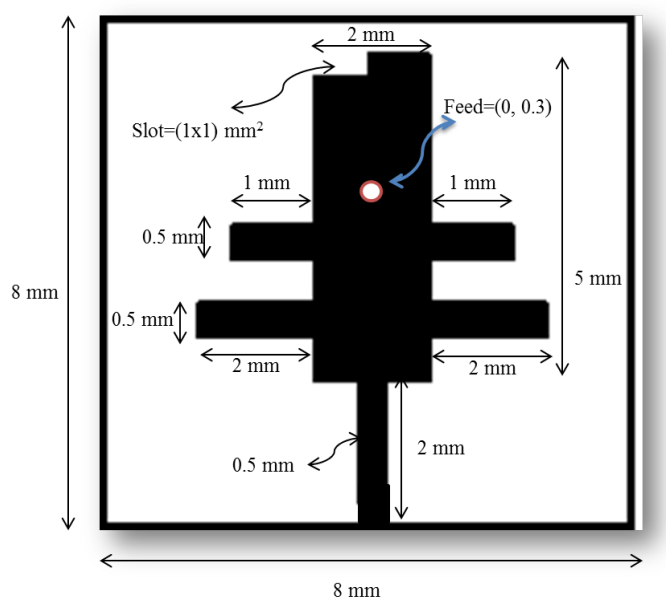

(a) Top view

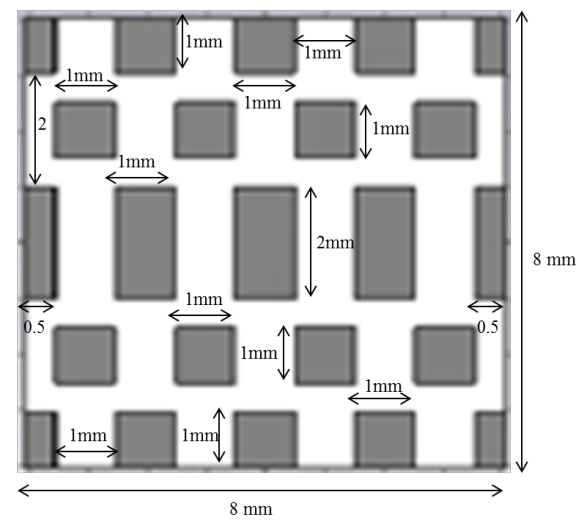

(b) Bottom view

Figure 1: Geometry of the antenna

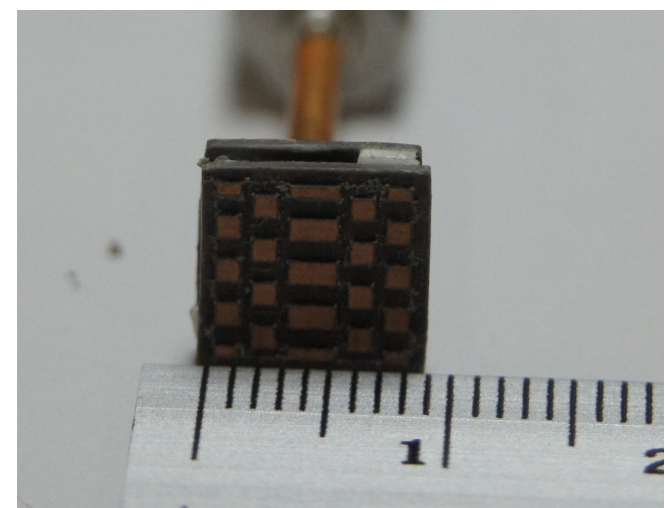

(a)

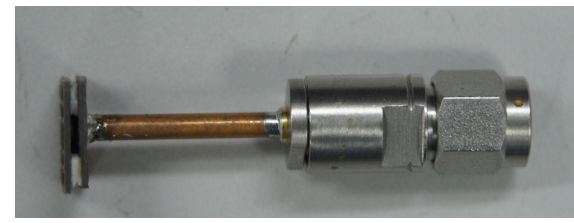

(b)

Figure 2: Prototype antenna with Port Extension (magnified image)

\section{Results and Measurements}

The proposed antenna has been fully optimized in order to obtain the desired antenna characteristics. First the lower structure has been optimized for a slotted rectangular patch and then the upper layer structure has been optimized very carefully to obtain dual band characteristics. For the complete simulation process, 3D EM simulation software has been used and Agilent vector network analyzer has been used for measurement purpose. Fig. 3(a) shows the Sparameters study of lower layer of the proposed antenna design. It can be seen from the graph that the antenna is resonating at two different frequencies i.e. $16 \mathrm{GHz}$ and 30 $\mathrm{GHz}$ thus providing dual band characteristics. At lower frequency, the antenna is giving an impedance bandwidth of about $500 \mathrm{MHz}$ and at the higher resonating frequency; the antenna is showing an impedance bandwidth of about 700 $\mathrm{MHz}$ with a return loss of $31 \mathrm{~dB}$ and $33 \mathrm{~dB}$ respectively at $10 \mathrm{~dB}$ reference. Fig. 3(b) shows the S-parameter study of the two-layer final proposed structure. The antenna is resonating at two frequencies i.e. $16 \mathrm{GHz}$ and $30 \mathrm{GHz}$. By incorporating this upper layer consisting of different size element array results in the overall enhancement of impedance bandwidth and improvement in the radiation properties. The bandwidth at the lower frequency is about $500 \mathrm{MHz}$ but the bandwidth at the higher frequency has increased to about $1 \mathrm{GHz}$. Fig. 4 shows the impedance matching. The simulated and measured results are in good agreement.

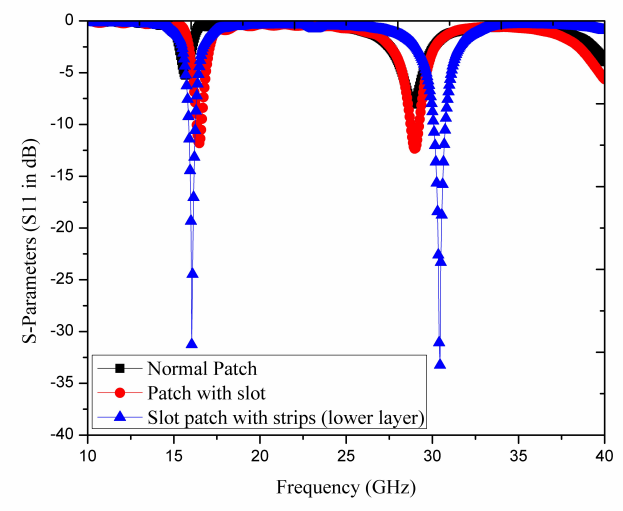

(a)

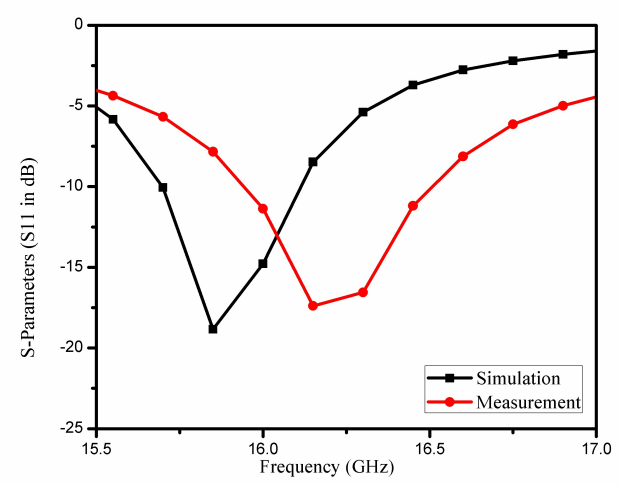

(b) 


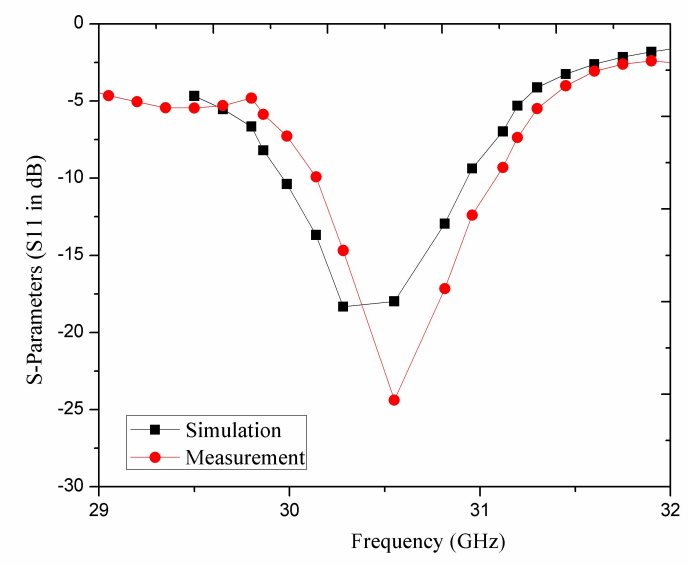

(c)

Fig. 3. S-Parameter $(\mathrm{dB})$ variation with frequency $(\mathrm{GHz})$ (a) For Lower layer (b) For proposed antenna (Ku) (c) For proposed antenna (Ka)

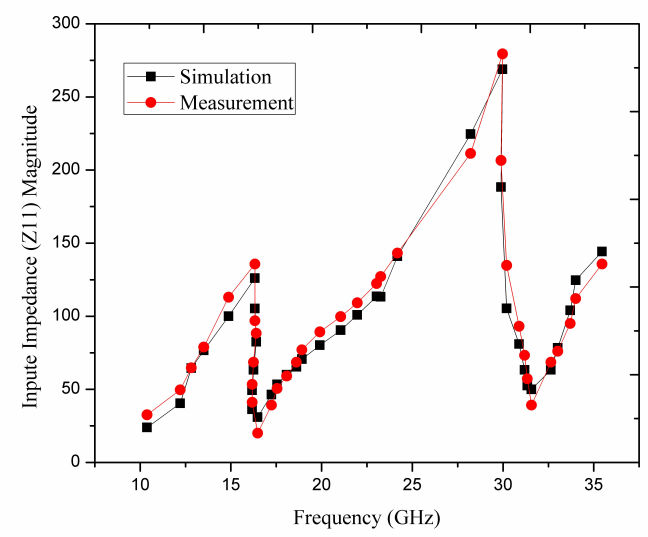

Fig. 4. Input Impedance (magnitude) for proposed antenna

Fig. 5 is showing the surface current distribution for the proposed antenna design. Fig. 5(a) shows the distribution at lower resonant frequency and 5(b) shows the distribution at higher resonant frequency. From the figures, we can clearly see the high current density areas at the two frequencies.

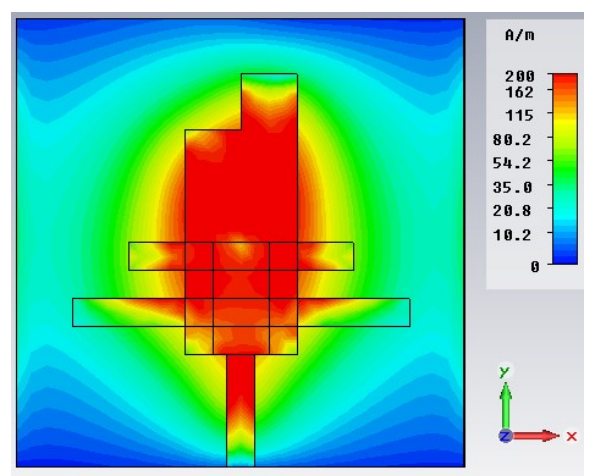

(a)

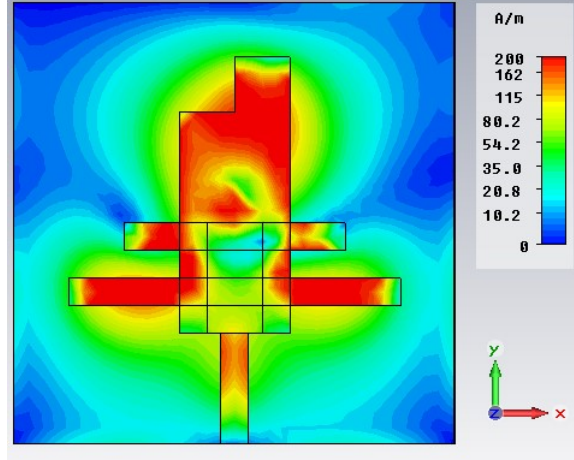

(b)

Fig. 5. Surface current distributions (Proposed antenna)

(a) At $16 \mathrm{GHz}$ (b) At $30.45 \mathrm{GHz}$

The gain and side lobe variations have been shown in fig. 6 and 7 for the lower layer and final two layers proposed structure respectively. With one layer, the antenna is showing a gain of about $6.9 \mathrm{dBi}$ and $5.9 \mathrm{dBi}$ at the two resonant frequencies respectively.

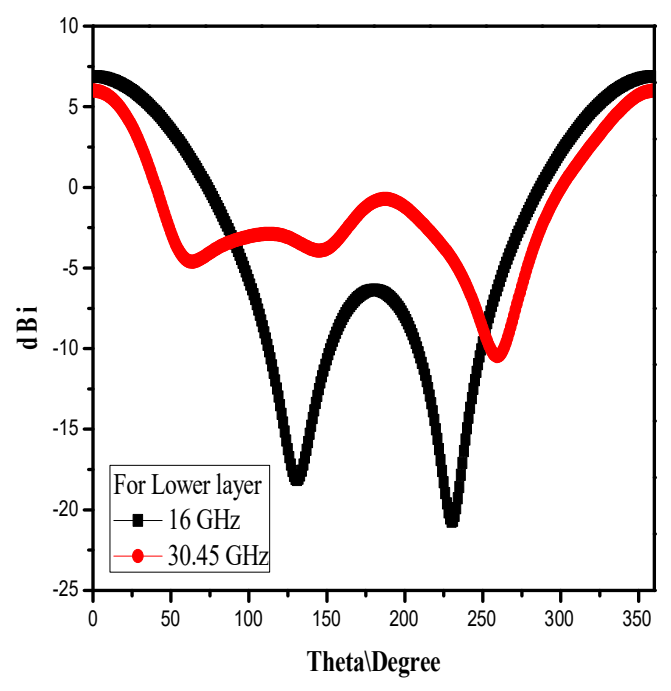

Fig. 6. Gain variation for Lower layer

For the final two-layer structure, the antenna is providing a gain of about $7.0 \mathrm{dBi}$ and $7.8 \mathrm{dBi}$ at the two resonating frequencies. The YZ-plane and XZ-plane have been shown in the graphs separately for both resonant frequencies. It can be clearly analyzed from here that the two-layer structure is giving better antenna characteristics which is very essential for high frequency applications. Also the side lobe levels have been reduced to a good extend of around $-12 \mathrm{~dB}$ at the resonating frequency. 


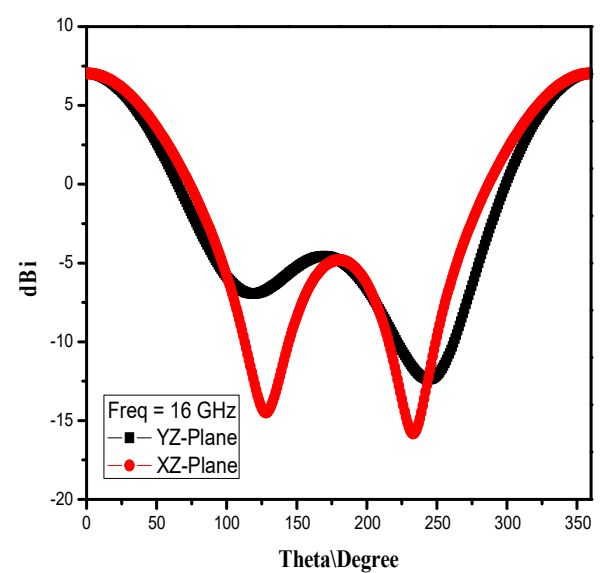

(a)

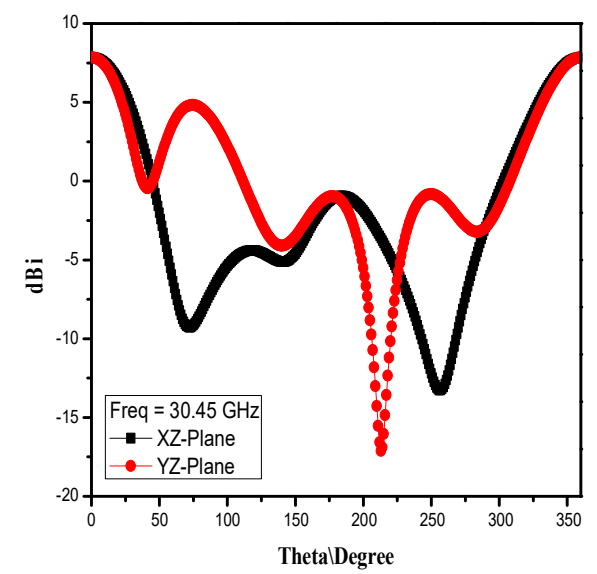

(b)

Fig. 7. Gain variation for proposed design
(a) $16 \mathrm{GHz}$
(b) $30.45 \mathrm{GHz}$

The normalized radiation patterns have been shown in fig. 8 . The co-polar and cross-polar components have been shown in polar plots for YZ-plane.

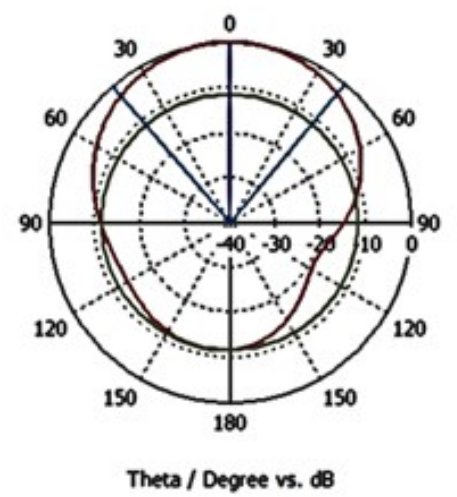

(a) Co-polar at $16 \mathrm{GHz}$

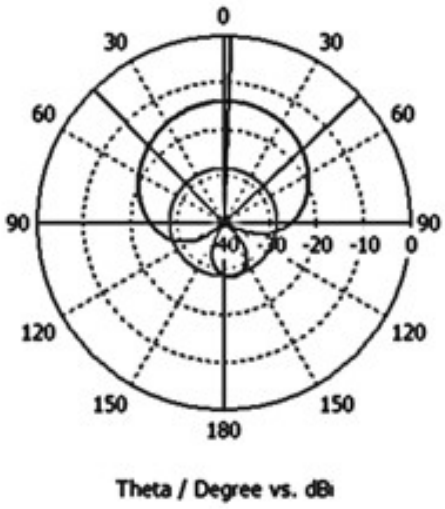

b) Cross-polar at $16 \mathrm{GHz}$

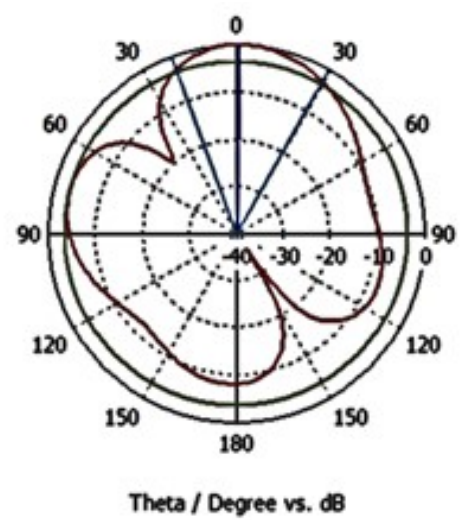

(c) Co-polar at $30.45 \mathrm{GHz}$

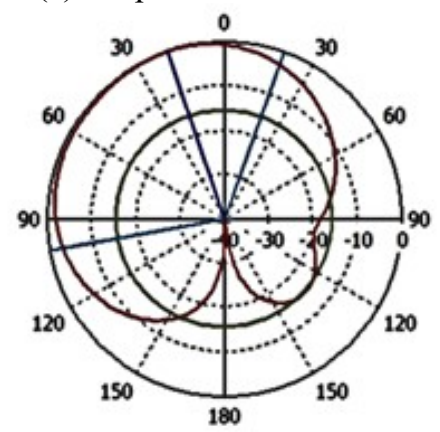

Theta / Degree vs. de

(d) Cross-polar at $30.45 \mathrm{GHz}$

Fig. 8. Normalized radiation patterns for proposed design

Therefore, it can be analyzed from the results obtained for the proposed two-layer compact antenna design that the antenna is providing very good properties in terms of bandwidth, directivity, side lobe levels, especially for high frequency applications i.e. Ku-band and Ka-band. In particular, the frequencies of operation of the proposed antenna also makes it suitable candidate for satellite communications and vehicle speed detecting radars. Due to its overall compact thickness of just $2.702 \mathrm{~mm}$, it also 
fulfills the criteria of miniaturization and compactness thus making it efficient and useful design for dual frequency operation and integration with other microwave and millimeter wave circuits.

\section{Conclusions}

A novel compact antenna design has been proposed for dual band operation with good radiation properties in $\mathrm{Ku}$ and $\mathrm{Ka}-$ band. The frequency of operation makes it a very useful candidate for high frequency applications especially where the dual band or multiband characteristics are required. The antenna is also providing a very good directivity of $7.8 \mathrm{~dB}$ along with reduced losses in terms of the side lobe levels at higher frequencies. Further the antenna can be easily integrated with the microwave and millimeter wave circuits due to its very compact size thus providing the ease of integration property also.

\section{Acknowledgements}

Author is highly thankful for the lab facilities provided by the National Science and Development Agency of Thailand.

\section{References}

[1] A. Colin, "A $30 \mathrm{GHz}$ Bow-tie Slot Antenna Fed by a Microstrip to CPW Transition," Progress in Electromagnetics Research Symposium Proceedings, Moscow, Russia, August 18-21, pp. 883-885, 2009.

[2] M. M. Islam, M. T. Islam, andM. R. I. Faruque, "DualBand Operation of a Microstrip Patch Antenna on a Duroid 5870 Substrate for Ku- and K-Bands," Hindawi Publishing Corporation, The Scientific World Journal, Volume 2013, Article ID 378420, 10 pages, http://dx.doi.org/10.1155/2013/378420, 2013.

[3] C.-M. Wu, "Dual-band CPW-fed cross-slot monopole antenna for WLAN operation," IET Microwaves, Antennas and Propagation, vol. 1, no. 2, pp. 542-546, 2007.

[4] G. Augustin, S. V. Shynu, P. Mohanan, C. K. Aanandan, and K. Vasudevan, "Compact dual-band antenna for wireless access point," Electronics Letters, vol. 42, no. 9, pp. 502-503, 2006.

[5] C. P. Hsieh, T. C. Chiu, and C. H. Lai, "Compact dualband slot antenna at the corner of the ground plane," IEEE Transactions on Antennas and Propagation, vol. 57, no. 10, pp. 3423-3426, 2009.

[6] M. T. Islam, N. Misran, and A. T. Mobashsher, "Compact dual band microstrip antenna for Ku-band application," Information Technology Journal, vol. 9, no. 2, pp. 354-358, 2010.

[7] I. J. Bahl and P. Bhartia, Microstrip Antennas, Artech House, Boston, Mass, USA, 2nd edition, 1980.

[8] R. Azim, M. T. Islam, andN.Misran, "Dual polarized microstrip patch antenna for Ku-band application," Informacije MIDEM, vol. 41, no. 2, pp. 114-117, 2011.
[9] A. Sayed, R.S. Ghonam and AbdelhalimZekry, "Design of a Compact Dual Band Microstrip Antenna for $\mathrm{Ku}$ Band Applications," International Journal of Computer Applications (0975 - 8887), Volume 115, No. 13, pp. 11-14, April 2015.

[10] D. M. Pozar, "Microstrip Antennas", Proceedings of IEEE, Vol. 80, No. 1, 1992.

[11] S. V. Shynu, R. K. Raj, A. R. Chandran, C. K. Aanandan, P. Mohanan, and K. Vasudevan, “Single-feed dual-frequency dual polarized microstrip antenna with hexagonal slot," in IEEE Antennas Propagation Society Int. Symp. Digest, vol. 4, pp. 4380-4383, 2004.

[12] L. Zaid, G. Kossiavas, J. Y.Dauvignac, J. Cazajous, and A.Papiemik, "Dual-frequency and broadband antennas with stacked quarter wavelength elements," IEEE Trans. Antennas Propag., vol.47, no. 4, pp. 654 $660,1999$.

[13] C. A. Balanis, Antenna Theory: Analysis and Design, 3rd Ed. Wiley, 2005.

[14] R. Che, B. Dong, and C. Yu, "Study and design of $\mathrm{Ku}$ band direct broadcast satellite microstrip antenna array,"Proceedings of ICCTA, 2009.

[15] H.-H. Hsieh, Y.-C.Hsu and L.-H. Lu, "A 15/30-GHz dual-band multi-phase voltage-controlled oscillator in 0.18-mm CMOS," IEEE Transactions on Microwave Theory and Techniques, vol. 55, no. 3, pp. 474-483, March 2007.

[16] H. A.Majid, M. K. A. Rahim, M. R. Hamid, and M. F. Ismail, "A compact frequency-reconfigurable narrowband microstrip slot antenna," IEEE Antennas and Wireless Propagation Letters, vol. 11, pp. 616-619, 2012. 